demonstrated in small amounts. Liver function tests on that day were as follows:

Total bilirubin $1.1 \mathrm{mg} . / 100 \mathrm{ml}$; conjugated bilirubin $0.6 \mathrm{mg} . / 100 \mathrm{ml}$; alanine transaminase 60 I.U.; alkaline phosphatase 10 K.A. units; thymol turbidity 1 ; thymol flocculation 0 ; colloidal gold 0 .

Iprindole was withdrawn, and the patient made a complete recovery within a few days and remains well physically. The liver function tests, when repeated on 16 January showed:

Total bilirubin $0.5 \mathrm{mg} . / 100 \mathrm{ml}$; ; conjugated bilirubin $0.3 \mathrm{mg} . / 100 \mathrm{ml}$; ; alanine transaminase 4; alkaline phosphates, thymol turbity, thymol flocculation, and colloidal gold were all within normal limits.

The second case was a 49-year-old man who was seen on 1 October 1969 with a moderately severe endogenous depression and iprindole 2 tablets t.d.s. were prescribed, together with nitrazepam $10 \mathrm{mg}$. at night. This was his first surgery attendance for five months. By 10 October his depression had improved and the iprindole was repeated. He was next seen at home on 14 October, having taken to bed on 11 October with fever and malaise. Minimal icterus was apparent when he was seen, but the urine gave a negative response to Ictotest. Iprindole was discontinued and when he was seen on 17 October no jaundice was apparent. However liver function tests done on 19 October were as follows:

Total bilirubin $1.8 \mathrm{mg} . / 100 \mathrm{ml}$; conjugated bilirubin $1.2 \mathrm{mg} / 100$; alanine transaminase 17 I.U.; alkaline phosphatase 19 K.A. units; thymol turbidity 1; thymol flocculation 0 ; colloidal gold 0 .

At this stage he was prescribed amitriptyline and he continued to recover.

These cases show that hepatotoxic reactions can occur in response to this drug which rapidly resolve when it is withdrawn. Perhaps it is significant that in both cases the drug had been administered for one week before the reactions appeared.

We should like to thank Dr. G. A. Faux of the medical department of John Wyeth and Bro. Ltd. for his help with the presentation of these cases.

-We are, etc.,

J. C. Newell Price.

J. A. Collings-Wells.

Fleet, near Aldershot,

\section{Value of Culdocentesis}

SIR,-I would endorse the findings of Drs. Cynthia Lucas and A. M. Hassim (24 January, p. 200) as reported in their paper on culdocentesis and ectopic pregnancies.

In the years 1968-9, 14 cases of ectopic pregnancy were admitted in this hospital (30 surgical beds). This represents $12 \%$ of all major surgical emergencies during this period. Culdocentesis was performed in 10 of these patients and in every case confirmed the diagnosis. There was no doubt in the diagnosis of the remaining four cases, and laparotomy was carried out immediately. There was one false-positive result which at laparotomy turned out to be a rupture of the uterus due to chorioncarcinoma (biopsy). In another patient, despite a negative result from culdocentesis, laparotomy was performed only to reveal a pyosalpinx. There have been no maternal deaths in this small series.-I am, etc.,

\section{Cost of Anaesthetic Agents}

SIR,-I am sorry that Mr. G. TeelingSmith (4 April, p. 52) finds it "distressing" to have to spell out that the cost of delivering domiciliary oxygen is bound to be high, particularly when I had granted this point in my original letter. It was not the fact but the size of the price differential that I was querying.

However, there is another price differential whose very existence I find puzzling. The total cost to the N.H.S. of a 48 cu.ft. (1.4 cu.m.) cylinder, excluding the chemist's delivery charge, is 37s. 6d., of which the Drug Tariff component is $27 \mathrm{~s}$. The same cylinder if delivered to my dentist, who uses considerably less oxygen than at least one of my patients, costs 13s. 9d. Why?

My own experience suggests that the use of domiciliary oxygen is on the increase. If so, distribution costs should fall and we can hope for a price reduction.-I am, etc.,

Edinburgh 6.

JohN S. PATterson.

\section{Unexpected Danger of Diazepam}

SIR,-The report by Drs. S. A. Feldman and B. E. Crawley (14 March, p. 691) on the apparent potentiation of nondepolarizing muscle relaxants by diazepam (Valium), prompts me to suggest a possible synergism between it and methaqualonediphenhydramine (Mandrax).

A patient during recovery from an overdose of the latter became difficult to manage on account of hyperpnoea, restlessness, muscular hypertonia, intermittent tremor, and trismus. An intravenous injection of diazepam $10 \mathrm{mg}$. was followed by apnoea and muscular relaxation. Tracheal intubation was easily performed, and he was mechanically ventilated without attempts at spontaneous respiration for two hours. After recovery of spontaneous respiration no further difficulty in his management was experienced.-I am, etc.,

ANDREW Doughty.

Intensive Care Unit,
Kingston Hospital,

Kingston Hospital,
Kingston-upon-Thames, Surrey.

\section{Fibrinolytic Activity in Pregnancy}

SiR,-Recently I had an opportunity of studying the blood fibrinolytic activity in a 24-year-old woman who was taking a combined oestrogen-progestogen contraceptive pill (Ovulen). The woman stopped taking the pill in order to be able to conceive. A close check was kept on her fibrinolytic activity during the whole of the pregnancy as well as the post-partum period (Graph). The blood fibrinolytic activity was estimated by the euglobulin lysis time (E.L.T.) method described by von Kaulla modified and using an E.L.T. recorder, ${ }^{1}$ and expressed in units by multiplying the reciprocal of the lysis times in minutes by 10,000 .

There was no difference in the blood fibrinolytic activity during the period when the pill was taken and the period immediately after withdrawal of the drug.

However, within four weeks of conception the blood fibrinolytic activity had decreased and this fall persisted during the whole of the pregnancy. It must be pointed out that the decrease observed four weeks after conception was proved to be due to pregnancy only retrospectively. A further reduction in blood fibrinolytic activity was noted during the last trimester of the pregnancy.

On examination one week after delivery the blood fibrinolytic activity had returned to normal levels, which is in agreement with the findings reported by other workers. ${ }^{2-4}$ Though decreased blood fibrinolytic activity during pregnancy has been observed ${ }^{356}$ a survey of the literature has failed to reveal any studies where this has been estimated immediately before and soon after a pregnancy in the same woman.-I am, etc.,

\section{SUDHAKARAN MENON.}

\section{Department of Medicine, \\ Royal Victoria Infirmary and \\ Newcastle upon \\ REFERENCES}

Menon, I. S., Martin, A., and Weightman, D.,

odgkinson, C. P., Margulis, R. R., and Luzadre, J. H., Four Clinical Pathology, 1958, 11, 306.

Shaper, A. G., Macintosh, D. M., and Kyobe, J., Lancet, 1966, 2, 874.

5 Menon, I. S., Clinician, 1970, 34, 9.

Wardle, E. N., and Menon, I. S., British Medical fournal, 1969, 2, 625 . Laboratory Practice, 1969, 18, 1186

Biezenski, J. J., and Moore, H. C., foumal of 